\title{
Just how prepared can we expect new medical graduates to be?
}

\author{
Emma Salisbury, Andrew Frankel
}

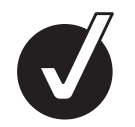

THE PROBLEM

In December 2010, The Lancet published the findings of EDITOR'S a global independent comCHOICE mission of 20 professional and academic leaders who came together to develop a shared vision and a common strategy for education in medicine. ${ }^{1}$ Their problem statement was damning, "...fresh health challenges loom.... Professional education has not kept pace with these challenges, largely because of fragmented, outdated and static curricula that produce ill-equipped graduates." ${ }^{1}$ They urged 'concerned stakeholders' to join them in 'rethinking for reforms of professional education' and in response, in 2011 the General Medical Council (GMC) published the first edition of a report entitled 'The state of medical education and practice in the UK'. ${ }^{2}$ The GMC is ultimately responsible for determining and assuring quality of the outcomes of medical education and training in the UK, and sets out the standards for undergraduate education in the document 'Tomorrow's Doctors 2009'.

The 'fresh health challenges' referred to by The Lancet report describe the advance of modern medicine seen by industrialised nations such as the UK, combined with better hygiene, vaccination programmes and greater relative affluence. People are living longer, but with a growing burden of chronic disease. The public has also become better educated and more informed, assisted by the information technology revolution. ${ }^{2}$ These factors have placed increasing demands on the healthcare service, as well as contributing to an altered doctor-patient relationship with a new emphasis on partnership and negotiated care. ${ }^{2}$ As pressure on the healthcare service has mounted, tensions have grown between service delivery and protected time for medical education and training. ${ }^{2}$

Renal Department, Imperial College Healthcare NHS Trust, London, UK

Correspondence to Dr Emma Salisbury, 1 Atalanta Street, London SW6 6TU, UK;

emmasalisbury@doctors.org.uk
The knowledge, skills and behaviour that undergraduates need to learn at UK medical schools are set out by the GMC which stipulates that newly graduated doctors, 'must be able to demonstrate all the outcomes in 'Tomorrow's Doctors 2009' in order to be properly prepared for clinical practice and the Foundation Programme.' ${ }^{3}$ The Foundation Programme, a two-year generic training programme which forms the bridge between medical school and specialist/ general practice training in the UK, builds on undergraduate education, allowing new doctors to apply their knowledge and demonstrate performance in the workplace. The programme should allow the doctor in-training to experience a range of clinical placements which include caring for acutely ill patients and those with chronic diseases. The attainment of competence which is at the core of the Foundation Programme can be described on the 'Dreyfus \& Dreyfus' five-stage model of skill acquisition shown in table $1{ }^{4}$

Apprentice-style undergraduate teaching on clinical attachments has been restricted in recent years by the formal recognition of National Health Service (NHS) patients' rights in the first (and now abolished) Patient's Charter of 1991, and the shadow of an increasing litigation culture drifting over the Atlantic from the USA. ${ }^{5}$ This has provoked recent reports suggesting that new doctors are not gaining the necessary clinical experience at undergraduate level and are starting their first posts as foundation doctors ill-prepared, a theme once again brought to the fore by Tallentire et al in their review published in Postgraduate Medical Journal. ${ }^{7}$ At the same time, medical education has been squeezed from the postgraduate side by the full implementa-

Table 1 'Dreyfus \& Dreyfus' five-stage model of skill acquisition ${ }^{4}$

\begin{tabular}{ll}
\hline Level 1 & Novice \\
Level 2 & Advanced beginner \\
Level 3 & Competent \\
Level 4 & Proficient \\
Level 5 & Expert \\
\hline
\end{tabular}

tion of the European Working Time Regulations into the UK on 1 August 2009. These regulations limit foundation doctors to a maximum of 48-hour week, averaged over a 6-month period, further heightening the tension between service delivery and protected time for medical education and training. In June 2010, the 'Temple Report' was published in response to concerns expressed by senior doctors that the European Working Time Regulations prevented them from ensuring that foundation doctors acquired a sufficient number of hours of supervised and hands-on experience to bring them up to an adequate standard. $^{8}$ The details of the report are beyond the remit of this editorial but suffice to say, the report concluded that high-quality training can be delivered in $48 \mathrm{~h}$ and made a number of recommendations on how this could be achieved.

\section{SO, AT THIS CRITICAL TIME FOR MEDICAL EDUCATION, WE ASK OURSELVES 'JUST HOW PREPARED CAN WE EXPECT NEW MEDICAL GRADUATES TO BE?'}

Competence is not a singular concept but a point on the road to professional expertise. ${ }^{9}$ It requires specific knowledge, practiced skill and appropriate attitude. Development of competence in different contexts and content areas will proceed at different rates ${ }^{10}$ and the outcomes set out in 'Tomorrow's Doctors 2009'3 present variable challenges in teaching and assessment. However, all graduates appointed to the Foundation Programme clearly need to be equipped with the knowledge and skills necessary to contribute positively to the provision of safe, high-quality patient care from their first day as new doctors.

In 2008, the GMC commissioned the report, 'How prepared are medical graduates to begin practice?'11 The experiences and perceptions of graduates at three UK medical schools differing in curriculum and/or entry cohort were studied using a mixture of qualitative and quantitative methods to provide a broad triangulated view of 'preparedness'. The report concluded that all three medical schools fulfilled the criteria set out by 'Tomorrow's Doctors 2009'3 but once again, highlighted a need for undergraduates to gain clinical experience. ${ }^{11}$ Research should guide change and indeed the GMC published the document, 'Clinical placements for medical students' in February $2011^{12}$ as supplementary advice to 'Tomorrow's Doctors 2009'. ${ }^{3}$ The report provides pointers for medical schools on how they can work to achieve compliance with 'Tomorrow's 
Doctors 2009' in relation to clinical placements, at a time when their relationship with local NHS services may be challenged by the pressure on budgets for all services. ${ }^{12}$

After a recent study of 300000 hospital admissions found a small but significant increase in mortality in August, attributed to the influx of newly qualified doctors, ${ }^{13}$ 'Tomorrow's Doctors 2009' recommended that all final-year undergraduates undertake a structured shadowing period within the foundation posts that they would be commencing work in. ${ }^{3}$ Shadowing offers an ideal opportunity for appointees to familiarise themselves with the work environment and to be introduced to the clinical team they will be joining. ${ }^{14}$ They can question the outgoing foundation year 1 (F1) doctor about the nuances of the role and get a clinical handover about the patients for whom they will be responsible. Furthermore, the appointee gains a real-life appreciation of the "first day competences' required to work as an F1 doctor. At the time of writing this Editorial, the Medical Education England Shadowing Steering Group has made the recommendation that by July 2012 all F1 appointees should spend at least four remunerated days shadowing the F1 job that they will be taking up. ${ }^{14}$

In addition to these changes being made at a national level, new teaching methods are also being promoted and curricula altered at local levels. In response to concerns voiced by one of its NHS trusts, the East Anglian Foundation School moved Advanced Life Support training from foundation year 2 to F1, resulting in improved confidence among its F1 doctors and a reduction in critical incidents involving F1 doctors and the deteriorating patient. ${ }^{15}$ Inspired by East Anglia's success, this curriculum change is due to be rolled out in other deaneries later this year.

The development of increasingly sophisticated simulation training is, meanwhile, offering opportunities to expose trainees of all levels to challenging clinical scenarios and a multi-sensory environment, useful in the assessment of knowledge, clinical reasoning and teamwork, while protecting patient safety. ${ }^{10}$ The London Deanery's and NHS London's Simulation and Technology-enhanced Learning Initiative is an award-winning flagship project which contributed to the Chief Medical Officer's report 'Safer Medical Practice: Machines, Manikins and Polo Mints'. ${ }^{16}$ It promotes the use of simulation and e-learning to enrich the delivery of healthcare professional workforce training and 'Hospital at Night Simulated Enhanced Learning', 'Emergency Medicine patient safety course', 'Patient Centric Healthcare' and 'Safety Skills in Surgery' are just some of the resources available.

In conclusion, preparedness for practice is a critical success factor in the transition from undergraduate to new doctor. Much has been done to address the issues surrounding this preparation in the very recent past and so, it is reassuring to see the first evidence of improvement emerging. The 'Foundation Programme Annual Report 2011' has just reported a year-onyear decline in the number of foundation doctors reported as in 'difficulty' since 2009. ${ }^{17}$ Ultimately, as Professor Sir Peter Rubin said in his November 2011 letter to all GMC-registered doctors, '....It is one thing to learn how to do a procedure; it's quite another to have the judgement to know whether to do it in the first place....' Competency is central to the practice of high-quality medicine and it requires specific knowledge, practiced skill and appropriate attitude. Graduates cannot be expected to be proficient in every area of their work when newly qualified, but they can be expected to contemplate their competences on a daily basis. ${ }^{9}$ They will often be the first doctor to be called to assess a patient. Being able to recognise when they have reached the boundaries of their competence, and need to give away ownership of the care of the patient to the team leader, is an essential skill to learn. For, the same duties apply to every doctor, trainee or expert, registered with the GMC:

- Provide a good standard of practice and care $^{18}$

- Keep your professional knowledge and skills up to date.

- Recognise and work within the limits of your competence.

- Work with colleagues in the ways that best serve patients' interests.
Contributors ES wrote the Editorial with the assistance of $A F$.

\section{Competing interests None.}

Provenance and peer review Commissioned; externally peer reviewed.

Published Online First 7 June 2012

Postgrad Med J 2012;88:363-364.

doi:10.1136/postgradmedj-2011-130709

\section{REFERENCES}

1. Frenk J, Chen L, Bhutta Z, et al. Health professionals for a new century: transforming education to strengthen health systems in an interdependent world. Lancet 2010;376:1923-58.

2. The State of Medical Education and Practice in the UK. London: General medical Council, 2011.

3. Tomorrow's Doctors. London: General Medical Council, 2009

4. Dreyfus S, Dreyfus H. A Five-Stage Model of the Mental Activities Involved in Directed Skill Acquisition. Washington, DC: Storming Media, 1980.

5. Department of Health. The Patient's Charter. London: HMSO, 1991.

6. Complaints and Litigation. London: House of Commons Health Committee, 2011.

7. Tallentire V, Smith S, Skinner J, et al. The preparedness of UK graduates in acute care: a systematic literature review. Postgrad Med J Published Online First: 13 December 2011. doi:10.1136/postgradmedj-2011-130232

8. Temple J. Time for Training. A Review of the Impact of the European Working Time Directive on the Quality of Training. London: Medical Education England, 2010.

9. Glazebrook W. Professionalism: Competency in Practice. Foundation e-Learning Programme, 2011.

10. Epstein R. Assessment in medical education. N Engl J Med 2007;356:387-96.

11. Illing J, Morrow G, Kergon C, et al. How Prepared are Medical Graduates to Begin Practice? A Comparison of Three Diverse UK Medical Schools London, UK: GMC Education Committee, 2008.

12. Clinical Placements for Medical Students. London: General Medical Council, 2011.

13. Jen M, Bottle A, Majeed A, et al. Early In-Hospital Mortality following trainee doctors' first day at work. PLOS ONE 2009:4:1-5.

14. MEE Shadowing Steering Group On National Shadowing Arrangement for Appointees to the Foundation Programme. London: Medical Education England, 2011.

15. Burns A, Jennings A. Preparation for professional practice for F1 trainees. Cambridge, UK: East of England Multiprofessional Deanery, 2009.

16. Safer medical practice: machine, manikins and polo mints. Chief Medical Officer Annual Report. London, UK: Department of Health, 2008.

17. Foundation Programme Annual Report. National (UK) Summary. London, UK: The UK Foundation Programme Office (UKFPO), 2011.

18. Good Medical Practice. London, General Medical Council, 2006. 